\title{
DA GÉNESE AO ENSINO DA QUÍMICA VERDE
}

\author{
Adélio A. S. C. Machado* \\ Departamento de Química da Faculdade de Ciências da Universidade do Porto, R. Campo Alegre, 687, Porto 4169-007, Portugal
}

Recebido em 15/7/10; aceito em 5/10/10; publicado na web em 26/1/11

\begin{abstract}
GREEN CHEMISTRY - FROM ITS BIRTH TO ITS TEACHING. An analysis of the activities that contributed to the birth of Green Chemistry (GC) about twenty years ago has shown that it emerged in response to the problems of pollution and wastes felt by the Chemical Industry. This close connection between GC and the Chemical Industry is similar to that found earlier between Chemistry and Industrial Chemistry before they separated. It was also found that since its very beginning the Chemical Industry has occasionally practiced GC. Broad implications of these findings to the teaching of GC are discussed.
\end{abstract}

Keywords: Green Chemistry; Industrial Chemistry; early green chemistry.

\section{INTRODUÇÃo}

Este artigo analisa o processo de emersão da Química Verde (QV) nos anos 80/90 do século XX, na esteira do movimento do moderno ambientalismo, surgido nos anos 60/70, e do conceito de Desenvolvimento Sustentável (1987). ${ }^{1}$ A análise mostra que a QV emergiu como resposta aos problemas que, neste contexto, a Indústria Química/Química Industrial vinha sentindo de forma crescente quanto à produção de resíduos (e poluição). A origem industrial da força motriz que potenciou a QV é a mesma que, no século XIX, contribuiu para o desenvolvimento da moderna Química Pura a partir da Química Industrial. A Química Industrial surgiu no século XVIII, nos primórdios da Revolução Industrial, com a invenção, nomeadamente, da câmara de chumbo como reator para o fabrico do ácido sulfúrico (Roebuck, 1746), ${ }^{2}$ e do processo Leblanc (1791) para o fabrico do carbonato de sódio (soda), ${ }^{3}$ cuja conceção foi incentivada por um concurso, com prémio pecuniário, aberto em França por iniciativa do rei Luís XVI, tal era a carência sentida pelo composto. A comparação destas datas com o ano de publicação do Traité Élémentaire de Chimie de Lavoisier (1789), o marco histórico habitual do nascimento da moderna Química Pura, sugere que esta foi precedida pela Química Industrial ou, talvez melhor, que as duas foram emergindo simultaneamente. As duas relações em sequência temporal, Química Industrial/Química, com dois séculos, e Resíduos da Química Industrial/QV, com duas décadas, indicam ambas a importância da tecnologia como base da química. O artigo analisa também a prática histórica da Química Industrial com vista a evidenciar que, em variadas situações ao longo do tempo, esta foi evoluindo no sentido de perseguir a "verdura" hoje preconizada pela QV, tendo começado a praticar muito cedo processos químicos com características de verdura.

Estes fatos têm implicações, quer quanto à natureza da química como ciência, quer quanto à sua reformatação para a QV, quer, muito especialmente, quanto ao ensino desta, às quais os químicos e, nomeadamente, os professores de Química, devem estar atentos - pelo que parece importante chamar a sua atenção para eles. Este é, afinal, o objetivo fundamental deste artigo.

*e-mail: amachado@fc.up.pt

\section{CONCEITOS QUE PRESSIONARAM A EMERSÃO DA QV}

A emersão da QV foi impulsionada pelo desenvolvimento de um certo número de atividades no âmbito da Indústria Química que conduziram a novas atitudes e conceitos (ver lista no Quadro 1), na década de 80 do século passado, no contexto da consolidação do ambientalismo moderno. O quadro contém duas partes: a primeira refere-se à evolução das reações da Indústria Química ao problema da produção de resíduos e poluição; ${ }^{4,5}$ a segunda, a novos conceitos a que essa evolução conduziu, já nos inícios dos anos 90, no âmbito da Química Laboratorial de síntese (economia atómica; ${ }^{6}$ e utilização atómica e fator $E{ }^{7,8}$ ver adiante), e que contribuíram para formatar os dois primeiros dos Doze Princípios da QV, formulados uns anos depois.9-11

As entradas do quadro vão ser brevemente discutidas a seguir, com o objetivo fundamental de mostrar as suas relações com a QV, para cuja emersão foram importantes ou contribuíram - bem como a participação da QV nas respetivas atividades no presente, se ocorre. Um objectivo acessório da discussão é contribuir para evitar as confusões que alguns dos termos listados na primeira parte do Quadro 1 provocam, porque, às vezes, ainda são usados quase como alternativas a QV, competindo com esta designação.

Quadro 1. Conceitos e atividades precursoras da QV

Com origem na Química Industrial/Indústria Química

Prevenção da poluição $\left(\mathrm{P}_{2}\right)$

Minimização de resíduos

Processos com mais segurança inerente

Cuidado Responsável

Design para o ambiente

Ecologia industrial

Com origem na Química Laboratorial/Química Académica

Economia atómica/Utilização atómica/Fator E

\section{O ATAQUE AO PROBLEMA DOS RESÍDUOS PELA QUÍMICA INDUSTRIAL}

A crescente tomada de consciência pela Indústria Química, na década de 80 , de que a resolução do problema da poluição e dos resíduos por acoplamento de equipamento de fim de linha às instalações industriais vigentes era pouco eficaz, bem como, paralelamente, o desenvolvimento 
de práticas de conceção de produtos industriais e processos de os manufacturar dirigidas ao uso eficiente dos materiais (desmaterialização) e ao aumento da produtividade industrial, induziram uma série de atitudes inovatórias que culminaram na QV. Estas são apresentadas a seguir pela ordem do Quadro 1, que procurou ser a cronológica; no entanto, muitos destes esforços foram realizados em paralelo, pelo que esta tentativa de ordenação cronológica tem um valor relativo.

\section{Prevenção da poluição}

A prevenção da poluição (abreviadamente, $\mathrm{P}_{2}$ ) foi prescrita pelo Pollution Prevention Act (EUA, 1990) para reduzir a quantidade de poluentes e resíduos produzidos genericamente pelos processos industriais e, naturalmente, adquiriu desde logo grande relevância no campo da Indústria Química. ${ }^{12-14}$ A prevenção da poluição significou uma profunda mudança de paradigma de gestão ambiental: ${ }^{15}$ ao contrário das estratégias de controlo de poluição clássicas, baseadas na retenção dos poluentes após a sua produção, visava privilegiar a alteração do processo químico e o aumento da sua eficiência para reduzir a quantidade de poluentes e resíduos formados nas instalações industriais; no entanto, na prática, dadas as dificuldades de atuar deste modo, englobava um conjunto de outras atividades de diferente natureza, nomeadamente de reciclagem, enumeradas no Quadro 2 (por ordem decrescente de eficácia). ${ }^{16}$

Quadro 2. Atividades de prevenção de poluição $\left(\mathrm{P}_{2}\right)$

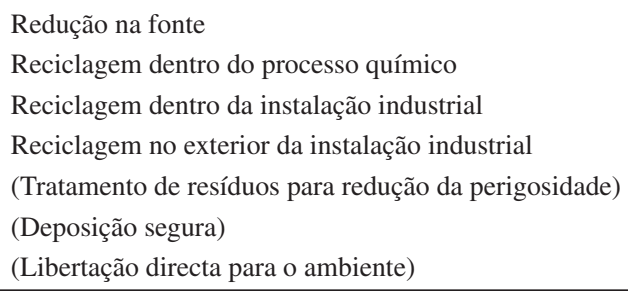

Uma das ideias base da futura QV, traduzida pelo Primeiro Princípio (Princípio da Prevenção), ${ }^{9-11}$ estava embutida preferencialmente nas primeiras atividades da lista no Quadro, e muito em particular na primeira, a redução na fonte, dado o seu objetivo fundamental de minimizar ou eliminar poluentes e resíduos de natureza química, provenientes dos processos da Indústria Química e similares. Em geral, a conotação da QV com as atividades do fim da lista, tais como o tratamento de resíduos e a deposição segura, é ténue. Estas últimas, quando praticadas atualmente, tal como as restantes atividades industriais da tecnosfera, constituem processos industriais que devem ser realizados com respeito pelo ambiente, pelo que podem exigir contribuições de QV. É claro que a última atividade da lista, a libertação directa para o ambiente, é a antítese da QV, só podendo ser aceitável para substâncias inócuas, se as há. ${ }^{17}$

\section{Minimização de resíduos}

As atividades de minimização de resíduos integram a $\mathrm{P}_{2}$, mas são aqui mencionadas explicitamente porque surgiram na Indústria Química de forma independente e mais intencionalmente dirigida directamente ao problema dos resíduos. ${ }^{18-20} \mathrm{~A}$ minimização de resíduos (ou o sinónimo redução de resíduos) refere-se à diminuição da quantidade de resíduos sólidos e líquidos produzidos por um processo (o conceito não abarca a poluição atmosférica); por vezes, a estratégia de redução descrita pelo termo inclui também a reciclagem no interior no processo, e mesmo a recuperação e tratamento seguro de resíduos sólidos ou líquidos. Além disso, na estratégia podem também ser incluídas operações de manejamento de resíduos - referentes, por exemplo, ao uso de embalagens seguras e etiquetagem clara dos resíduos, etc., para evitar acidentes.

Dada a sua ligação mais directa à Química, o conceito de minimização de resíduos terá contribuído mais intensivamente para a QV que a $\mathrm{P}_{2}$, embora presentemente tenha um nível inferior ao da QV na hierarquia da prevenção da poluição, já que a QV prescreve (idealmente!) a eliminação da produção de resíduos.

\section{Processos com mais segurança inerente}

Este termo refere-se à emersão de uma nova postura no design dos processos industriais da Indústria Química, que preconiza um esforço incisivo e continuado de perseguição de segurança pelos engenheiros químicos logo no desenvolvimento dos processos químicos de fabrico de compostos, para eliminar de raiz os perigos das instalações (ou, pelo menos, diminuir os riscos de desastres). Esta nova atitude, que surgiu na esteira do acidente de Flixborough, ${ }^{21} \mathrm{e}$ foi proposta por T. Kletz, em 1977, corresponde a uma inovadora mudança de paradigma na abordagem da segurança na Indústria Química - abandonou a prática clássica que usava o design para fazer a gestão e controlo dos riscos de acidente, no fim do desenvolvimento do processo, sem desafiar antes a respetiva inevitabilidade, substituindo-o pelo design de processos com maior segurança embutida pelo próprio design como objetivo intencional deste. ${ }^{22} \mathrm{~A}$ maior segurança inerente afasta os perigos proativamente, de forma permanente e inseparável do processo, em vez de os deixar existir e ter de lidar com eles reativamente. ${ }^{23}$

Esta postura foi apropriada pela QV, quer diretamente, já que é explicitamente expressa no Décimo Segundo Princípio da QV (Princípio da Química Inerentemente Mais Segura), ${ }^{9-11}$ quer mais difusamente, mas com maior alcance, quando a QV ampliou a sua aplicação para montante do desenvolvimento do processo, isto é, para a química de base - prescrevendo-a para a conceção dos próprios compostos e respetivas vias de síntese. Nunca é demais realçar a importância da ideia da segurança embutida por design como base da QV: afinal de contas, obter segurança - física, toxicológica, ambiental, na Sustentabilidade, etc. - é o objetivo genérico desta.

Neste contexto, tem interesse notar que quer o design do processo inerentemente mais seguro quer a minimização de resíduos surgiram no âmbito da química em resultado de diversas forças motrizes comuns sentidas coletivamente pela Indústria Química, que impulsionaram também a QV. Estas são listadas no Quadro 3 (respigado da ref. 24).

Quadro 3. Forças motrizes comuns ao processo inerentemente mais seguro, à minimização de resíduos e à QV

Não tolerância por incidentes com implicações exteriores à instalação (por exemplo, fugas e explosões)

Preocupações crescentes da sociedade por todos os tipos de impactos ambientais (consciencialização crescente da necessidade do Desenvolvimento Sustentável)

Legislação e regulamentação ambiental crescente em número, variedade e alcance

Custos crescentes do tratamento de resíduos e da segurança reativa clássica (obtida por meio de "camadas de proteção")

Supervisão e controlo governamental crescente das operações de fabrico industrial

Consciencialização empresarial crescente quanto ao valor da minimização de resíduos, dos processos mais inerentemente seguros e da QV para a atividade de negócios e para os clientes 


\section{Cuidado Responsável}

O programa Cuidado Responsável é uma iniciativa voluntária da Indústria Química que tem como objetivo melhorar a sua atuação com respeito à saúde humana, segurança e ambiente. Aquando do seu lançamento, a iniciativa correspondeu a outra postura inovadora no tratamento das questões ambientais - a cooperação proativa da indústria na resolução antecipada dos problemas, cujo acicate teve uma forte componente económica: evitar os custos que a via legislativa envolve (estruturas internas da empresa para garantir o cumprimento da legislação, realização de análises químicas para aferir a contaminação, eventuais processos judiciais e multas, etc.).

O programa teve origem no Canadá, em 1985, estendendo-se depois aos EUA (em 1988, por ação do American Chemistry Coun$c i l,{ }^{25}$ a associação das empresas da Indústria Química daquele país) e a muitos outros países. O seu lançamento e desenvolvimento no âmbito da atividade da Indústria Química nestes dois países foram despoletados pela ocorrência do desastre de Bhopal (1984), ${ }^{26}$ o maior acidente industrial de todos os tempos até agora ocorrido (a influência do desastre de Bhopal no modo de lidar com os problemas de segurança da Indústria Química desenvolvido na Canadá é discutida, por exemplo, na ref. 27).

Pode-se encontrar mais informação sobre o Cuidado Responsável na respetiva página da Internet ${ }^{28} \mathrm{e}$ uma revisão crítica do programa na ref. 29. O programa funciona agora (2009) em 53 países, que no seu conjunto produzem cerca de $90 \%$ da produção mundial de produtos químicos, e é presentemente gerido a nível global pelo International Council of Chemical Associations (ICCA), que monitoriza a sua implementação e assegura a sua evolução para que possa responder às preocupações e questões atuais. Cada associação nacional gere o seu próprio programa com as respetivas companhias. As companhias que aderem voluntariamente ao programa ${ }^{30}$ assumem o compromisso de melhorar a sua atuação em domínios variados, por exemplo, proteção ambiental, saúde e segurança ocupacional, segurança das instalações, domínio e logística do produto no mercado, relações com a vizinhança e o público em geral, etc., independentemente de requisitos impostos pela legislação vigente - em suma, responsabilizam-se por melhorar continuadamente os produtos que fabricam e os respectivos processos de manufactura para incrementar a proteção ambiental e da saúde humana e ecológica, e a segurança dos empregados, moradores na vizinhança e população em geral, etc.

O Cuidado Responsável ajuda a Indústria Química a operar com segurança e com cuidado pelas gerações futuras (presentemente o programa é dirigido explicitamente ao Desenvolvimento Sustentável) - sem perder de vista o objetivo de aumentar os respectivos lucros. Através da permuta de informação e de um sistema de controlo de atuação (listas de análise de processos, indicadores de performance, procedimentos de verificação, etc.), as empresas aderentes adquirem informação que demonstra a sua conduta responsável, mais concretamente, a melhoria de atuação ao longo dos anos, e podem definir uma política de melhoramento contínuo no futuro. O programa exige que as empresas divulguem a informação aos seus parceiros exteriores (comunidades locais, autoridades governamentais, meios de comunicação, etc.) - obrigando-as, assim, a trabalhar de modo aberto e honesto. Para poder funcionar em muitos países de todo o mundo, o programa é intencionalmente flexível - com vista a acomodar as diferenças culturais, legislativas, etc.

A comparação dos Princípios Orientadores do Cuidado Responsável (ACC, EUA, 1991) ${ }^{31}$ com os Doze Princípios da QV ${ }^{9-11}$ mostra que o Cuidado Responsável tem preocupações e objetivos parcialmente coincidentes com a QV, embora mais diretamente focados na atividade da Indústria Química e seus efeitos a jusante - em particular, tal como a QV, assume que a via legislativa não é a mais adequada para resolver os problemas de saúde humana, ambientais, etc.

Em suma, embora não dirigido explicitamente à QV, o Cuidado Responsável teve um papel importante na sua gestação, porque consolidou a ideia de que a proatividade é mais eficaz que a reatividade para lidar com os problemas provocados pelos produtos químicos - e permite compreender bem porque a $\mathrm{QV}$ começou por ganhar alento no ambiente industrial, não no académico.

\section{Design para o ambiente}

O termo design para o ambiente (DfE, Design for Environment $)^{32}$ designa a conceção (design) de produtos e processos feita de raiz para que tenham impactos mínimos no ambiente. ${ }^{33-35}$ Como logo no fim do design de um objeto e em virtude deste, fica fixada uma larga fração, da ordem de $80 \%$, dos respectivos impactos ambientais, o DfE assume como objetivo a minimização desses impactos desde o início do trabalho de conceção do produto e do processo para o fabricar requer que em todas as etapas do design, quer do produto quer do processo, se tomem medidas proativas que reduzam ou eliminem eventuais efeitos negativos no ambiente (uma postura semelhante à da Industria Química quanto à segurança inerente, ver atrás). Por exemplo, favorece o design do produto por módulos, quando possível, para que no fim-de-vida estes possam ser desmontados, remanufacturados ou reciclados; ou o uso de materiais recicláveis ou obtidos de matérias-primas renováveis, etc.

A designação DfE emergiu no princípio dos anos 90 do último século, como resultado cumulativo de esforços realizados desde os anos 70 com vista a otimizar o design de objetos, nomeadamente, por exemplo, equipamento eletrodoméstico e/ou eletrónico, simultaneamente quanto a objetivos diversos. Em termos de design clássico, a definição do produto na fase de conceção tem de otimizar, por exemplo, o funcionamento e modo de utilização, as suas caraterísticas estéticas, a gama de custos, etc. A partir dos anos 70, novas caraterísticas de natureza diferente foram acrescentadas a esta lista, estabelecendo-se o chamado paradigma design para $X$ (DfX, design for $X$ ), em que $\mathrm{X}$ podia contemplar vários aspectos, por exemplo, DfC (C de cumprimento da regulamentação em vigor quanto ao objeto), DfM (M de manufacturabilidade, a facilidade de fabrico na linha de montagem), DfD (D de desmontabilidade, a facilidade de desmontagem para facilitar a recuperação de peças e reciclagem), etc. ${ }^{34} \mathrm{~A}$ lista de $\mathrm{X}$ foi crescendo, passou a incluir cada vez mais aspectos ligados ao ambiente, em sentido genérico, e, após a emersão da Ecologia Industrial (ver a seguir), passou a incluir o E (Environment) - em DfE o E pode incluir objetivos diversificados, dada a complexidade do ambiente. O DfX foi uma base importante para se chegar à Ecologia Industrial, embora o seu alcance seja muito mais restrito que o desta. Presentemente, o papel do DfE na Ecologia Industrial continua a ser vultuoso.

O DfE e a QV surgiram em consequência de esforços paralelos, o primeiro um pouco antes da segunda e numa perspetiva mais geral da engenharia, tendo possivelmente aberto caminho para a QV - no fundo, a QV pratica o DfE no domínio da química e os dois conceitos têm objetivos globais idênticos. As relações entre eles serão discutidas adiante.

\section{Ecologia Industrial}

A emersão da Ecologia Industrial ocorreu nos fins da década de 80, mais precisamente em 1989 - a data de publicação na revista Scientific American do que é geralmente considerado o artigo seminal no campo, por Frosch e Gallopoulos, ${ }^{36}$ embora a ideia tivesse sido "fermentada" antes. ${ }^{37.38}$ A Ecologia Industrial resultou dos problemas 
sentidos na reciclagem dos resíduos industriais, ${ }^{39,40}$ bastante difíceis de resolver com eficácia, e envolve uma nova visão dos sistemas industriais que prescreve atenção simultânea ao aprovisionamento de matérias-primas e à produção de resíduos, de modo a que tais sistemas operem de modo semelhante aos ecossistemas naturais, em que os materiais nutrientes são movimentados continuadamente em ciclos fechados. Em vez do funcionamento linear em regime aberto dos sistemas industriais clássicos (extrair as matérias-primas do subsolo, fabricar bens, usá-los e depor os respectivos resíduos no ambiente), será preferível montar sistemas alternativos fechados que possibilitem utilização mais eficiente dos materiais, com fluxos no interior do sistema, em percurso fechados, estabelecidos por uma rede complexa de interações - tais sistemas implicam muito mais autossuficiência do uso de materiais, com menores interações com o ambiente. Para isso, é preciso que os materiais e objetos criados pela tecnologia e os respectivos processos de fabrico sejam concebidos adequadamente para facilitar a integração do sistema industrial (tecnosfera), e dos restantes sistemas artificiais usados pelo Homem para viver (antroposfera), no invólucro ambiental em que se suportam, o ambiente (ecosfera), de forma sustentável. Em resumo, o objetivo global da Ecologia Industrial é promover a conceção de materiais e processos de fabrico inovatórios que permitam esta integração - essencial para se conseguir chegar ao Desenvolvimento Sustentável.

A Indústria Química, sendo uma componente importante do sistema industrial, tem obviamente de se integrar na Ecologia Industrial. No entanto, como os produtos químicos são usados em muitas outras indústrias, e muitas delas envolvem processos químicos, e todos os bens e materiais são substâncias químicas, a química tem um papel central na Ecologia Industrial e, naturalmente, a importância da QV para o Desenvolvimento Sustentável é fulcral. A relação entre estes conceitos, discutida a seguir, fará sentir melhor a influência que a Ecologia Industrial teve na emersão da QV, mais por criação de ambiente propício do que por efeito directo, já que os dois ramos só foram explicitamente associados já nos finais do século XX ${ }^{41}$

\section{QV e DfE na Ecologia Industrial}

A QV tem objetivos semelhantes ao DfE, na medida em que persegue a descoberta e fabrico de produtos químicos recicláveis, não tóxicos, obtidos a partir de reagentes de origem renovável, etc. Assim, a QV surge ao mesmo nível do DfE no âmago da Ecologia Industrial, como se esquematiza na Figura 1 (parte superior) - formam ambas o "coração" deste ramo de conhecimento aplicado, sendo complementares. ${ }^{41} \mathrm{Na}$ realidade, as respetivas filosofias básicas são idênticas: tal como sucede no DfE, para dar frutos na prevenção de resíduos, eliminação de efeitos tóxicos, etc., a QV tem de ser aplicada logo nas primeiras fases da conceção de produtos e processos químicos - ou seja, afinal, a QV visa implementar o DfE no domínio da química. Por outro lado, como a QV fabrica os materiais usados nos processos de fabrico de bens manufacturados concebidos pelo DfE, este fornece a informação e compreensão de alterações requeridas nos materiais e nos respectivos processos químicos de fabrico - daí a complementaridade, em que a QV dá o empurrão tecnológico e o DfE o puxão tecnológico sobre a Ecologia Industrial, para usar a linguagem da inovação da tecnologia (a parte inferior da Figura 1 resume graficamente esta ideia).

Finalmente, na Figura 1 (parte superior) inclui-se também o Desenvolvimento Sustentável, evidenciando que se trata de um conceito mais amplo, do qual a QV é uma componente importante. O Desenvolvimento Sustentável envolve, além das facetas tecnológicas e ambientais da QV e do DfE, uma forte componente social - possibilitando mudanças de outro tipo que não as tecnológicas do âmbito da Ecologia Industrial, por exemplo, a contenção do consumo de bens em favor da

\section{COMPLEMENTARIDADE QV - DfE}
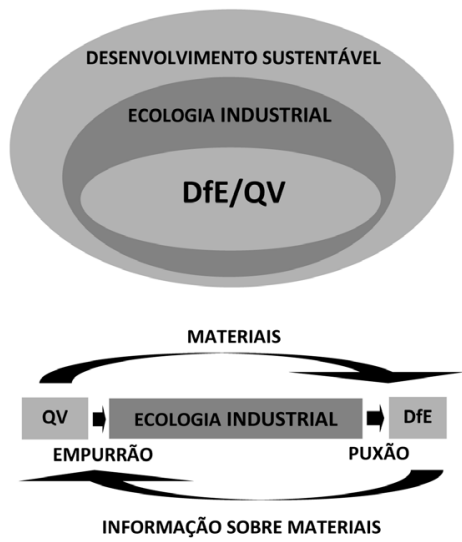

Figura 1. Relação entre a QV, o DfE, a Ecologia Industrial e o Desenvolvimento Sustentável. Em cima, as relações entre os quatro conceitos. Em baixo, o papel da QV e do Dfe na Ecologia Industrial

sua conservação, ou o uso do transporte colectivo em vez do automóvel para utilização pessoal, por opção individual ou societária. A inserção e papel da QV na Sustentabilidade é um tema muito complexo mas muito importante para o desenvolvimento de ambas - que, embora não caia fora do âmbito do presente artigo, o alongaria demasiado.

\section{TOMADA DE CONSCIÊNCIA DO PROBLEMA DOS RESÍDUOS PELOS QUÍMICOS}

Numa discussão sobre a génese da QV é pertinente incluir uma importante mudança de postura dos químicos académicos de síntese, que foi também determinada pela crescente consciencialização sobre a gravidade do problema dos resíduos em Química Industrial. No início dos anos 90 do século XX, os químicos orgânicos de síntese tomaram finalmente consciência, após mais de século e meio a inventar novas moléculas no laboratório, ${ }^{42}$ que a arte da síntese consiste não só em obter o composto requerido, mas também em não obter paralelamente resíduos: um objetivo importante que as reações de síntese devem cumprir é incorporar os átomos aportados pelas moléculas dos reagentes na molécula do produto, não nas moléculas que se formam conjuntamente com esta, as quais, em princípio, dão origem a resíduos.

A mudança de visão sobre as reações de síntese, de reducionista para sistémica (ver adiante), resultou da introdução dos conceitos de economia atómica (Trost, 1991), ${ }^{6}$ e de utilização atómica e fator E (Environmental factor) (Sheldon, 1992) ${ }^{7,8}$ As definições destes conceitos são apresentadas no Quadro 4; o modo como se usam as massas de reagentes, produto e resíduos (coprodutos) para o seu cálculo é ilustrado graficamente na Figura 2. Os dois primeiros conceitos avaliam a extensão da incorporação dos átomos em jogo na reação, provenientes dos reagentes, no produto meta da reação. Essa extensão deve ser maximizada para que se perca a menor quantidade possível de átomos em resíduos - um objetivo tão importante como obter rendimento elevado. O fator $\mathrm{E}$, cada vez mais usado na química industrial de síntese, ${ }^{43}$ ao comparar a massa de resíduos com a de produto, põe em evidência a extensão do problema da produção de resíduos no fabrico de substâncias químicas. Os três conceitos servem de base a métricas de massa, usadas na avaliação da verdura da química (ver, por exemplo, ref. 44).

Estes novos conceitos para avaliar as reações químicas implicaram um modo inovador de olhar para a química de síntese, ilustrado na Figura 3 - passar a praticar a química de modo a otimizar o embuti- 


\section{PRODUTIVIDADE ATÓMICA}

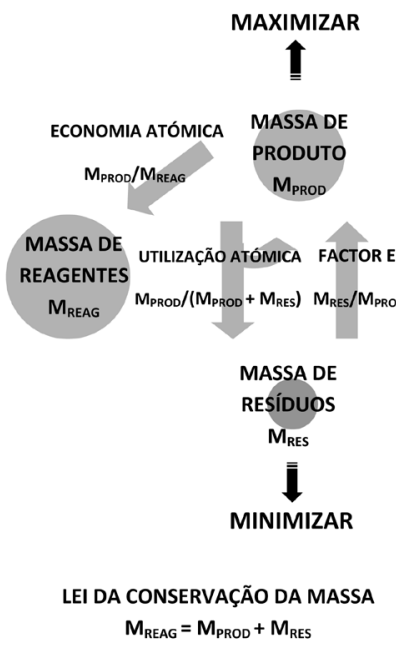

Figura 2. Nova postura dos químicos orgânicos de síntese envolvendo tanta atenção aos resíduos como ao produto. As setas a cinzento indicam como se calculam as razões que definem as grandezas

mento dos átomos proporcionados pelos reagentes no produto, para minimizar os resíduos. Posteriormente, os conceitos fundamentaram o Primeiro (Prevenção de resíduos) e Segundo (Economia atómica) Princípios da QV.9-11 A inovação pode ser expressa em linguagem económica: os químicos passaram a visar uma maior produtividade ${ }^{45}$ dos átomos, um dos fatores básicos que usam nas reações químicas (outro é a energia). O conceito de produtividade atómica foi introduzido na química mais recentemente que as grandezas definidas no Quadro 4, por Steinbach e Winkerback (2000). ${ }^{46}$ Uma análise detalhada da relação entre os conceitos foi apresentada na ref. 44.

Quadro 4. Conceitos químicos base da QV

\section{Economia atómica}

Razão entre a massa de átomos dos reagentes estequiométricos incorporados no produto desejado e a massa total de átomos nos reagentes, expressa em percentagem

\section{Utilização atómica}

Razão entre a massa de produto desejado e a soma das massas de todas as substâncias produzidas na reação (produto e coprodutos), expressa em percentagem

\section{Fator E}

Razão de massa entre a totalidade da massa dos resíduos produzidos e a massa do produto desejado, expressa em valor

A incorporação sistemática na Química, como objetivo fundamental, da otimização da produtividade atómica foi uma contribuição importante dos químicos de síntese na gestação da QV. No entanto, a força motriz deste modo inovatório de visualizar as reações químicas foi o problema dos resíduos, sentido cada vez mais prementemente pela Química Industrial após a emersão do ambientalismo.

A discussão anterior mostra que a emersão da QV não ocorreu subitamente, num momento de inspiração genial de um qualquer químico académico: as ideias base da QV foram o resultado de um longo processo de luta, por parte dos químicos industriais de processo e engenheiros químicos, para a tornar a Indústria Química menos nociva para o ambiente - em particular, para lidar mais eficazmente com a produção de resíduos e minimizar a sua quantidade. Este processo teve como última etapa a consciencialização dos químicos orgânicos de síntese para o problema dos resíduos, que possibilitou o "salto final" para a QV. Neste passo decisivo, ocorreu uma modificação da postura quanto ao modo como os resíduos eram vistos nas reações químicas: os resíduos, até então desprezados, a não ser quando podiam ser utilizados como reagentes ou vendidos como subprodutos, ganharam estatuto, passando a ser objeto de tanta atenção pelos químicos como o produto a preparar. Interessantemente, este fato foi reconhecido na ordenação dos dois primeiros dos Doze Princípios: o primeiro é o da Prevenção de Resíduos, o segundo o da Economia Atómica (incorporação de átomos no produto!) - embora não se possa garantir se esta ordem teve intenção ou não, porque os princípios foram apresentados sem grande discussão explicativa, ${ }^{9}$ o que, aliás, é compreensível porque são globalmente intuitivos, o fato é que, nos Doze Princípios, os resíduos tiveram prioridade sobre o produto!

\section{AS DUAS POSTURAS DA QUÍMICA E A MUDANÇA DE POSTURA NA QV}

A atividade no domínio da química, ao longo do século XIX, foi um aglomerado de ciência e tecnologia em que as duas componentes foram sendo desenvolvidas em paralelo, com integração mútua e sem grande diferenciação inicial - a química tecnológica proporcionou o desenvolvimento da Indústria Química e, ao mesmo tempo, a Química Pura foi avançando como ciência (do que resultou a Química ter sido a única ciência com uma indústria própria e um ramo de engenharia clássica próprio ${ }^{47}$ ). Com o aumento do conhecimento químico-físico, ${ }^{48}$ a visão da química a nível atómico-molecular foi aumentando e as técnicas de síntese que estão na base da "invenção laboratorial" de novas moléculas ("compostos sintéticos") foram avançando num contexto cada vez mais racionalista - na primeira metade do século XX, foi ocorrendo a crescente diferenciação da Química Pura (ou Académica), cada vez mais reducionista e dividida em campos especializados, da Química Industrial, que, naturalmente se manteve sistémica, em particular quando realizada por processos contínuos. Esta separação, que se completou em meados do século XX, quando a Química Académica passou a ser investigada e ensinada em campos cada vez mais estritos e quase estanques (por exemplo, Termodinâmica Química, Equilíbrio Químico, Cinética Química, etc), carece presentemente de ser revertida para facilitar o desenvolvimento da QV.

Na realidade, a génese da QV envolveu uma transição da química da postura reducionista do racionalismo cartesiano (raciocínio linear causa $\rightarrow$ efeito, com objetivo único: o produto da reação), para a postura sistémica (raciocínio por linhas paralelas, que não foge à complexidade, holístico, dirigido a objetivos múltiplos - envolvendo simultaneamente o produto e os resíduos). Na Figura 3 representa-se graficamente a mudança da natureza dos objectivos das duas posturas, para realçar a sua importância. Note-se, no entanto, que a figura é pobre quanto a esta intenção, já que ilustra apenas a duplicação de metas na manipulação dos átomos - mas a QV envolve também uma variada multiplicidade de objetivos dirigidos à conservação do ambiente, ao respeito pela saúde humana e ecológica, à preservação dos recursos naturais, etc., que têm de ser considerados todos em conjunto. ${ }^{49}$

A atitude sistémica da QV não é estranha à Química - pelo contrário, esteve na sua origem, já que fez desde sempre parte da Química Industrial: esta, tendo como acicate a manufactura de produtos químicos requeridos na esteira da Revolução Industrial, foi desenvolvida como uma tecnologia de produção industrial destes, portanto, naturalmente realizada em sistemas industriais. Por exemplo, ao longo do século XIX, quando a Química era ainda uma ciência empírica, apenas macroscópica, realizada com base na estequiometria das reações (o conhecimento sobre termodinâmica, equilíbrio e cinética, bem como sobre estrutura atómica e ligação química, etc., era vago ou mesmo nulo ${ }^{48}$ ), a Indústria Química montou o processo das câmaras de chumbo para o fabrico do ácido sulfúrico, um elaborado sistema industrial de processo contínuo. A câmara de chumbo, inventada por Roebuck 
COMPARAÇÃO DE OBJECTIVOS

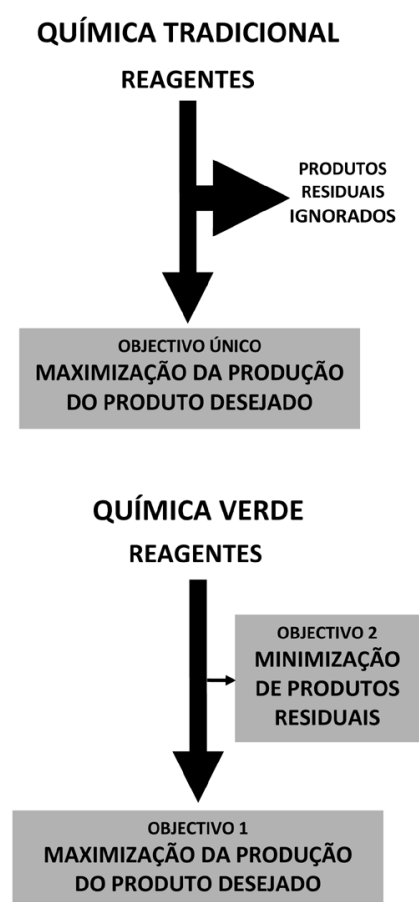

Figura 3. Comparação dos objetivos da química tradicional com a $Q V$. A QV tem um objetivo duplo: maximização do produto desejado e minimização de produtos residuais

(1746) para realizar o fabrico do ácido sulfúrico, foi o primeiro reactor específico da Química Industrial, marcadamente diferente dos vasos de reação usados no laboratório, servindo de cerne à montagem do sistema: posteriormente, foram-lhe acopladas torres de absorção de gases, inventadas por Gay-Lussac (1827) e Glover (1859), para reter e reciclar os óxidos de azoto usados como catalisadores (ver adiante) e para permitir uma eficiente absorção do trióxido de enxofre e sua hidratação ao ácido, acabando por emergir um sistema para realizar o processo contínuo ${ }^{50,51}$ Este exemplo mostra uma faceta importante dos sistemas, mesmo os artificiais: a sua capacidade para evoluir e aperfeiçoar-se para melhor cumprir o objetivo, desde que este esteja bem definido, mesmo quando o saber científico de base é limitado - o que, afinal, ilustra a tremenda capacidade inventiva da mente humana.

\section{AS RELAÇÕES HISTÓRICAS ENTRE A QUÍMICA INDUSTRIAL E A QV}

É também interessante referir que a História da Química mostra que, ao longo do tempo, se manifestou uma inter-relação da Química Industrial com a QV logo desde o século XIX: a Química Industrial foi desenvolvendo, aqui e ali, práticas que presentemente se podem considerar de QV - inserem-se bem nesta, podendo-se considerar exemplos temporãos de QV. Por exemplo, o trabalho de Alfredo Nobel, na segunda metade do século XIX, para preparar a nitroglicerina e permitir a sua utilização como explosivo de forma manejável (isto é, razoavelmente segura), permite afirmar que ele terá sido o "primeiro químico verde". ${ }^{2}$ Outro exemplo temporão de QV ocorreu na indústria do fabrico do carbonato de sódio (soda): foi a substituição do Processo Leblanc, produtor de resíduos volumosos e problemáticos (e sentido como extremamente poluente quando ainda não havia consciência da poluição!), pelo Processo Solvay, mais limpo, inventado cerca de $1860 .{ }^{53}$ Ainda outro exemplo, mais recente (1984), neste caso um mau exemplo (!), ocorreu na indústria de fabrico do pesticida carbarilo, na qual, em certas instalações, o processo montado inicialmente foi substituído por outro, que envolvia como intermediário o isocianato de metilo, um composto muito perigoso - esta mudança de um processo de síntese para outro muito mais problemático, afinal um retrocesso da QV (síntese verde substituída por "síntese vermelha"), foi a causa última do desastre de Bhopal. ${ }^{54}$

\section{Química Inorgânica Industrial}

Outro aspecto a salientar é que muitos dos processos industriais da Indústria Inorgânica para fabrico de compostos em grande escala, montados no século XIX e princípios do século XX, envolvem vias de sínteses verdes, pelo menos quanto à utilização dos átomos - incorporam todos os átomos, ou quase, no produto. Por exemplo, a via de síntese do ácido sulfúrico usada no processo das câmaras de chumbo, em que se reciclavam os óxidos de azoto usados como catalisadores, apresenta uma economia atómica de $100 \%$ - idealmente todos os átomos dos reagentes são incorporados no ácido: ${ }^{2}$

$$
\begin{gathered}
\mathrm{S}+\mathrm{O}_{2} \rightarrow \mathrm{SO}_{2} \\
\mathrm{NO}+1 / 2 \mathrm{O}_{2} \rightarrow \mathrm{NO}_{2} \\
\mathrm{SO}_{2}+\mathrm{H}_{2} \mathrm{O}+\mathrm{NO}_{2} \rightarrow \mathrm{H}_{2} \mathrm{SO}_{4}+\mathrm{NO} \text { (reciclado) } \\
\text { Total: } \mathrm{S}+3 / 2 \mathrm{O}_{2}+\mathrm{H}_{2} \mathrm{O} \rightarrow \mathrm{H}_{2} \mathrm{SO}_{4}
\end{gathered}
$$

Ao longo da primeira metade do século XX, o processo das câmaras de chumbo foi progressivamente substituído pelo processo de contacto (inventado por Phillips, em 1831), ${ }^{2}$ que envolvia a conversão catalítica do dióxido de enxofre a trióxido de enxofre por meio de um catalisador sólido (inicialmente de platina, depois substituído por $\mathrm{V}_{2} \mathrm{O}_{5}$, mais barato). Este processo evidencia melhor a economia atómica total da via sintética:

$$
\mathrm{S}+\mathrm{O}_{2} \rightarrow \mathrm{SO}_{2} \ldots+1 / 2 \mathrm{O}_{2} \rightarrow \mathrm{SO}_{3} \ldots+\mathrm{H}_{2} \mathrm{O} \rightarrow \mathrm{H}_{2} \mathrm{SO}_{4}
$$

A utilização de um catalisador sólido permitiu simplificar o processo industrial, o que se traduziu posteriormente na melhoria do respectivo controlo e segurança, bem como da qualidade do produto. Mais tarde, para impedir a libertação do dióxido de enxofre para a atmosfera imposta pelo ambientalismo, a legislação passou a exigir que a conversão $\mathrm{S} \rightarrow \mathrm{H}_{2} \mathrm{SO}_{4}$ fosse igual ou superior a $99,5 \%$, o que obrigou ao uso de conversores de passagem dupla (processo IPA, de inter-passagem). ${ }^{55}$ Depois, a crise do petróleo dos anos 70 do século XX induziu um novo aperfeiçoamento do processo: como todas as reações da via de síntese são fortemente exotérmicas e o calor libertado é muito elevado $\left(3,26 \times 10^{6} \mathrm{~kJ}\right.$ por tonelada de ácido sulfúrico), incrementou-se a recuperação de energia sob a forma de vapor. Como a energia química libertada no processo é excessiva relativamente aos requisitos energéticos do processo, o excesso passou a ser vendido, sob a forma de vapor, se havia mercado local para este, ou após produção de electricidade: por exemplo, uma instalação de capacidade 1000 toneladas de ácido por dia, ${ }^{56}$ permite montar uma pequena central termoeléctrica de 7,2 $\mathrm{MW} .^{55}$

Em suma, os processos de fabrico do ácido sulfúrico cumpriram princípios da QV muito antes da emersão desta, cujo número foi aumentando com a evolução da indústria ao longo do tempo: usaram vias de síntese com incorporação total dos átomos no produto (Princípios 1 e 2 da QV), baseadas em catalisadores (Princípio 9), e o processo de contacto atingiu elevada eficiência energética (Princípio 6) e possibilitou um controlo do processo melhor (Princípio 11) e maior segurança (Princípio 12).9-11 
O ácido sulfúrico sempre foi e continua a ser o composto manufacturado em maior extensão pela Indústria Química - o que, provavelmente, tem a ver com o fato de a sua via de síntese ser verde quanto à utilização de átomos, já que a mesma situação ocorre para outros compostos inorgânicos de base, nomeadamente para o amoníaco, sulfato de amónio, ácido nítrico e nitrato de amónio, todos fabricados por processos inventados nos princípios do século XX e basedos em vias de síntese catalíticas e com economias atómicas elevadas. A montagem de todos estes processos foi facilitada pela natureza simples e eficaz, quanto à utilização de átomos, da via de síntese.

\section{Química Orgânica Industrial}

Quanto à Indústria Química Orgânica, a situação histórica, embora diferente, é também interessante..$^{57} \mathrm{O}$ ramo da indústria pesada desenvolvido a partir dos anos 20 do século XX, com base na destilação do petróleo, inventou nos anos 40 processos contínuos com vias catalíticas, por exemplo, o craqueamento (craking) e a reforma (reforming) catalíticos, cujos objectivos eram aumentar, respetivamente, a quantidade de produtos leves (gasolina, etc.) e os respectivos índices de octanas; estes processos, montados por engenheiros químicos e químicos das superfícies e catálise e não a partir de vias de síntese obtidas no laboratório, promoviam uma melhor utilização dos átomos em produtos de qualidade funcional superior, mediante reações catalíticas - perseguiam assim a prática da QV!

Em contraste, a síntese orgânica desenvolvida pelos químicos no laboratório, na esteira das sínteses da malvina (Perkin, 1856) e de outros corantes sintéticos variados inventados subsequentemente, conduziu à indústria fina dos produtos químicos de especialidade, farmacêuticos, etc. Esta era (e é) praticada pelo processo das cargas, usando predominantemente reações estequiométricas, não catalíticas. ${ }^{58}$ As sínteses envolviam, por exemplo, oxidações com permanganato ou dicromato, reduções com hidretos metálicos e zinco, substituições aromáticas (halogenações, nitrações, sulfonações, etc.); frequentemente, na preparação de compostos aromáticos com moléculas elaboradas, procedia-se à introdução de certos grupos funcionais reactivos, como cloro ou nitro, em compostos intermédios, que se faziam reagir a seguir para os substituir pelos grupos funcionais requeridos no produto final. ${ }^{8}$ Este ramo da Indústria Orgânica era a antítese da QV, pois a utilização dos átomos era pobre: a maioria destes ia parar a resíduos, sendo os valores do fator E frequentemente superiores a $100 .{ }^{7} \mathrm{Na}$ realidade, estes processos químicos produziam tantos resíduos que acabaram por estimular o aparecimento das ideias base da QV (ver atrás), cujo campo de aplicação mais importante é justamente o da Indústria Orgânica Fina. Em suma, afinal, este ramo da Indústria Química, ou pela via verde ou pela "via vermelha" contribuiu para a emersão da QV. Este fato mostra que a História da Química, que faz parte da História em geral, não é linear, ${ }^{59}$ já que o reducionismo cartesiano que privilegia o racionalismo não permite interpretar toda a Química - e confirma que, também na Química Orgânica, a QV aparece associada à postura sistémica.

\section{IMPLICAÇÕES QUANTO AO ENSINO DA QV}

A prática da QV na Indústria Química, em termos globais, é ainda algo incipiente e precisa de ser desenvolvida, o que passa por lhe dar mais atenção no ensino da química. A lentidão do avanço da QV nos quase 20 anos que passaram desde que emergiu não é inesperada, por várias razões, nomeadamente: a Química Industrial é um sistema muito complexo, que envolve o fabrico de umas dezenas de milhar de compostos por dois ou três milhares de processos; as interrelações da Química Industrial com os seus múltiplos invólucros (ambiental, societal, económico, etc.) são numerosas e variadas; por outro lado, a QV implica uma mudança de paradigmas de prática da química - e as mudanças de paradigmas são sempre difíceis de realizar; e, ainda, muita da Química Pura desenvolvida nas últimas décadas ignorou requisitos essenciais para a sua aplicação industrial, pouco contribuindo para a Química Industrial, etc. Em consequência, a reformatação da química para QV é uma tarefa complexa e difícil, que exigirá um esforço persistente durante largos anos. Os químicos devem estar conscientes deste fato - até para não deixar esmorecer o seu entusiasmo em face das dificuldades com que se vão deparar.

A consideração simultânea da longa história da Química Industrial, da breve história da QV e da pré-história desta no âmbito da primeira, mostra a existência de uma relação de longa data entre as duas, apontando para que, no ensino da QV, se deva dar mais atenção ao contexto industrial e societal, em contraste com a tendência reducionista crescente que tem dominado a Química Pura no último meio século. A herança histórica evidenciada neste texto deve ser tida em consideração quando se pretende fazer evoluir o ensino da química para que possa suportar a QV. Tendo em vista este objectivo, a discussão anterior sugere duas recomendações de índole geral.

Primeira, como a QV tem um alcance lato, incluindo não só a Química Académica como também a Química Tecnológica, deve-se fazer inflectir o ensino da química para uma maior integração das duas. Esta posição foi, aliás, expressa no Relatório Breslow, ${ }^{60} \mathrm{da}$ National Academy of Sciences dos EUA, que discute conjuntamente o futuro da química e da engenharia química, quando os dois ramos eram objeto de relatórios separados em esforços anteriores do mesmo tipo. Para avançar na integração, os químicos devem ter em atenção os Doze Segundos Princípios da QV, introduzidos por Winterton (2001), ${ }^{61}$ infelizmente muito menos propagandeados que os Doze Primeiros, mas cuja prática facilitará a implementação de QV pela engenharia química. Também, para um bom entrosamento da QV com a Ecologia Industrial, será útil ter presentes os Doze Princípios da Engenharia Verde para a Ecologia Industrial. ${ }^{62}$

A segunda recomendação decorre de o ensino da QV, já que deve hoje ser dirigido para o Desenvolvimento Sustentável, exigir uma visão ampla e holística da química, de natureza sistémica, que possibilite a sua plena incorporação nos contextos ambiental, humano e societário em que a química sempre se desenvolveu e que são atualmente cada vez mais condicionantes da sua prática. Essa visão pode ser mais facilmente conseguida numa postura Ciência-TecnologiaSociedade (STS, mantendo a sigla inglesa) ${ }^{63}$ ou, em linguagem mais atual, Ciência-Tecnologia-Sociedade-Ambiente (STSE) ${ }^{64}$ ou mesmo, ainda mais atual, Ciência-Tecnologia-Sociedade-Sustentabilidade (STSS ou, em linguagem química, STS $_{2}$ ).

\section{CONCLUSÕES}

A matéria discutida neste artigo mostra que a génese da QV ocorreu no âmbito de uma mudança de paradigma de gestão das medidas para proteção ambiental desenvolvidas pela indústria, da postura reativa para a preventiva, que incorporou diversas componentes exploradas em paralelo e que foram emergindo com pouco distanciamento temporal na década de 80 do século passado (ver Quadro 1) - envolveu a conjugação de um conjunto de fatores exteriores à química, que se manifestam no seu invólucro tecnológico, ambiental e societal, com fatores intrínsecos da química, que também foram pressionados pelos primeiros. Além disso, mostra também que, muitos antes da emersão formal da QV, a prática da Química Industrial ao longo do tempo, embora casuisticamente, deu passos importantes que possibilitaram uma evolução não intencional (mas talvez não totalmente inocente!) dirigida para ela.

Estes fatos devem ser objeto de meditação quando se pretende incentivar o ensino e a prática da QV, que passa por dar mais atenção ao pensamento sistémico (sem menosprezar o reducionista - devem 
ser usados em paralelo!). Esta atitude de pensamento permite um melhor entrosamento dos ingredientes essenciais para o funcionamento dos sistemas (matéria, energia e informação), incluindo os sistemas químicos, e uma explicitação e análise das relações destes com os invólucros variados e complexos em que a química se insere.

Termina-se com uma nota mais ligeira. Os variados casos precoces de QV desenvolvidos pela Indústria Química ao longo da sua história são importantes, já que são animadores: dão confiança aos químicos quanto à sua capacidade para passarem a realizar a química com a nova postura da QV se atenderem aos seus objetivos - já que os seus colegas do passado, que não sabiam o que esta era, fizeram-na frequentemente (e quando a deixaram de praticar tiveram problemas, como em Bhopal).$^{54}$ Por isso, os químicos atuais podem manter-se otimistas ao realizar uma perseguição sistemática de verdura para desenvolverem a QV, essencial para o Desenvolvimento Sustentável.

\section{REFERÊNCIAS E NOTAS}

1. Brundtland, G. H., WCED (Presidente); Our Common Future, Oxford UP: Oxford 1997.

2. Roebuck, P.; Chem. Brit. 1996, 32, 38.

3. Campbell, W. A. Em Chemistry, Society and Environment - A New History of the British Chemical Industry; Russell, C. A., ed.; RSC: Londres, 2000, p. 75-106.

4. Mathews, M. M. Em Kirk-Othmer Encyclopedia of Chemical Technology; Seidel, A., ed.; Wiley: Nova Iorque, 2003, vol. 12, p. 799818.

5. Martell, A. E.; Davies, J. A.; Olson, W. W.; Abraham, M. A.; Annu. Rev. Environ. Resour. 2003, 28, 401.

6. Trost, B. M.; Science 1991, 254, 1471.

7. Sheldon, R. A.; Chem. Ind (London) 1992, 903.

8. Sheldon, R. A.; ChemTech. 1994, 24, 39.

9. Anastas, P. T.; Warner, J. C.; Green Chemistry - Theory and Practice, Oxford UP: Oxford, 1998, p. 30.

10. Machado, A. A. S. C.; Química - Bol. S. P. Q. 2004, 95, 59.

11. Lenardão, E. J.; Freitag, R. A.; Dabdoub, M. J.; Batista, A. C. F.; Silveira, C. C.; Quim. Nova 2003, 26,123.

12. Clean Production Strategies - Developing Preventive Environmental Management in the Industrial Economy; Jackson, T., ed., Lewis: Boca Raton, 1993.

13. Allen, D. T.; Rosselot, K. S.; Pollution Prevention for Chemical Processes, Wiley: Nova Iorque, 1997.

14. Mulholland, K. L.; Dyer, J. A.; Pollution Prevention: Methodologies, Technologies and Practices, AIChE: Nova Iorque, 1999.

15. Hirschhorn, J.; Jackson, T.; Baas, L. Em ref. 12, p. 125-142.

16. Um conceito análogo à prevenção da poluição, designado por produção mais limpa, foi desenvolvido no âmbito do UNEP (United Nations Environment Program), principalmente na Europa, ver: Jackson, T. Em ref. 12, p. 143-164.

17. Para ilustrar esta dúvida, pode referir-se o dióxido de carbono, um composto natural inócuo para a biosfera (e essencial para o suporte desta - é até um dos reagentes da fotossíntese!), mas cuja emissão para a atmosfera é conveniente restringir por causa da sua contribuição para o aquecimento global provocado pelo efeito de estufa.

18. Waste Minimisation: A Chemist's Approach; Martin, K.; Bastock, T. W., eds.; RSC: Londres, 1993.

19. Chemistry of Waste Minimization; Clark, J. H., ed.; Blackie: Londres, 1995.

20. Nemerow, N. L.; Zero Pollution for Industry - Waste Minimization through Industrial Complexes, Wiley: Nova Iorque, 1995.

21. O acidente ocorreu em Inglaterra, em Flixborough (Lincolnshire), em 1974, numa instalação de fabrico de caprolactam (composto usado no fabrico da fibra sintética nylon 6), operada pela empresa Nypro (UK); como provocou a morte de 28 trabalhadores da instalação e feriu outros 36 e mais 53 pessoas na vizinhança, bem como a destruição total da fábrica e danos nos arredores, mereceu enorme atenção pública - e contribuiu imenso para mudar a cultura da Indústria Química, bem como as expectativas da população e as políticas governamentais, sobre a segurança nas instalações industriais. $\mathrm{O}$ acidente teve como causa próxima a rutura de um tubo que tinha sido instalado provisoriamente para efectuar uma reparação, e que era inapropriado para resistir à pressão elevada do processo. A rutura provocou a libertação de uma nuvem de vapor inflamável (estimada em 40 toneladas de uma mistura em que predominava ciclo-hexano), que se incendiou e deu origem a uma explosão brutal - o incêndio continuou durante vários dias. $\mathrm{O}$ fabrico do caprolactam na instalação envolvia, como primeiro passo, a reação de oxidação em fase líquida de ciclo-hexano a uma mistura de ciclo-hexanona e ciclo-hexanol, com conversão de apenas $6 \%$, o que exigia equipamento volumoso (o processo integrava 6 reactores em série) e operações elaboradas de reciclagem e purificação - ou seja, o processo mantinha em inventário uma grande quantidade de compostos inflamáveis, sendo inapropriado quanto a segurança. Este defeito de conceção foi a causa fundamental, remota, do acidente. Uma descrição sumária do acidente e uma discussão breve mas elucidativa dos efeitos que teve no desenvolvimento posterior do design e manejo de processos da Indústria Química com vista a obter segurança pode ser encontrada em: Hendershot, D.; J. Chem. Health Saf. 2009, 16, 47.

22. O título do artigo em que Kletz apresentou a ideia base da nova postura (1977) é particularmente sugestivo quanto à sua natureza: “What you don’t have, can’t leak" - "O composto que não está lá (na instalação), não dá origem a fugas" (nem se incendeia, nem explode!). Pode encontrar-se a história da emersão desta ideia contada pelo próprio em: Kletz, T. K.; Process Saf. Prog. 1996, 15, 5.

23. Note-se que, após 30 anos de implementação continuada e crescente, se reconhece que a obtenção da segurança por inerência tem limitações, não dispensando a segurança reativa (ver, por exemplo: Hendershot, D.; J. Chem. Health Saf. 2010, 17, 29).

24. Mulholland, K. L.; Sylvester, R. W.; Dyer, J. A.; Environ. Prog. 2000, $19,260$.

25. Mais exatamente, a associação das empresas da Indústria Química dos EUA era então designada por Chemical Manufacturers Association, cujo nome mudou, em 2000, para American Chemistry Council $\left(\mathrm{AC}_{2}\right)$.

26. O acidente ocorreu em Bhopal, Índia, em 1984, numa instalação de fabrico do pesticida carbarilo, e provocou uns milhares de mortes imediatas, mais umas dezenas de milhar de vítimas não imediatamente mortais - o número exato de vítimas nunca chegou a ser apurado. $\mathrm{O}$ acidente resultou da adição inadvertida de água a isocianato de metilo contido num depósito, provocando uma reação que libertou calor e aumentou a pressão; este aumento levou à abertura da válvula de segurança de sobrepressão e à libertação de uma nuvem de vapor do referido composto, muito tóxico, que atingiu a cidade de Bophal. Passados 25 anos (2009), os efeitos deste acidente ainda não foram remediados, nem quanto ao pagamento de indenizações às vítimas, nem quanto à recuperação ambiental do local da instalação. $\mathrm{O}$ acidente mereceu na altura a publicação de um número especial do Chem. Eng. News (Chem. Eng. News 1985, 63(6), Fevereiro 11) que contém vários artigos que proporcionam uma visão global dos problemas que levantou (embora inicial e datada: o acidente tem sido, e continua a ser, discutido não apenas sob o ponto de vista da segurança industrial, mas de vários outros, incluindo fatores humanos e societais, por exemplo: regulamentação governamental da prática industrial, transferência de tecnologia para os países em desenvolvimento, compensação das vítimas, etc.). Uma breve descrição do desastre é incluída em: Machado, A. A. S. C.; Química - Bol. S. P. Q. 2010, 118, 41.

27. Lacoursiere, P. E. J. P.; J. Loss Prev. Proc. Ind. 2005, 18, 353. 
28. http://www.responsiblecare.org/page.asp?p=6341\&l=1, acedida em Janeiro 2011.

29. Givel, M.; Health Policy 2007, 81, 85.

30. Em certos países, a adesão à respectiva associação da Indústria Química obriga à adesão ao programa.

31. King, A.; Lenox, M.; Academy of Management J. 2000, 43, 698.

32. Esta designação aparece atualizada para design para o ambiente e sustentabilidade (Design for Environmentnt and Sustainability, DfES) num livro recente: Graedel, T. E.; Allenby, B. R.; Industrial Ecology and Sustainable Engineering, Prentice-Hall: Englewood Cliffs, 2010, p. 119.

33. Graedel, T. E.; Allenby, B. R.; Design for Environment, Prentice-Hall: Englewood Cliffs, 1996. 1998.

34. Fiksel, J.; Design for Environment, McGraw-Hill: Nova Iorque, 1996.

35. Ulrich, K. T.; Eppinger, S. D.; Product Design and Development, $3^{\text {rd }}$ ed., McGraw-Hill Irwin: Boston, 2004.

36. Frosch, R. A.; Gallopoulos, N. E.; Scient. Am. 1989, 261, 144.

37. Frosch, R. A. Em Technological Trajectories and the Human Environment; Ausubel, J. H.; Langford, H. D., eds.; NAP: Washington, 1997, p. 157-167.

38. Erkman, S.; J. Clean Prod. 1997, 5, 1.

39. Graedel, T. E.; Allenby, B. R.; Industrial Ecology, Prentice-Hall: Englewood Cliffs, 1995; idem, 2 ${ }^{\text {a }}$ ed., idem, 2003.

40. Industrial Ecology and Global Change; Socolow, R.; Andrews, C.; Berkhout; F.; Thomas, V., eds.; Cambridge UP: Cambridge, 1994.

41. Anastas, P. T.; Breen, J. J.; J. Cleaner Prod. 1997, 5, 97.

42. Há historicamente dois marcos importantes no desenvolvimento da Química Orgânica de síntese. A primeira síntese de uma molécula orgânica foi realizada em 1828, pelo químico alemão F. Wohler (18001882) - a ureia, $\left(\mathrm{NH}_{2}\right)_{2} \mathrm{CO}$; esta experiência marca o nascimento da própria Química Orgânica. O marco seguinte foi a síntese do primeiro composto orgânico artificial ("sintético"), o corante malvina ("mauveine"), por W. H. Perkin (1856), obtido inadvertidamente quando pretendia sintetizar o quinino.

43. Sheldon, R. A.; Green Chem. 2007, 9, 1273.

44. Machado, A. A. S. C.; Química-Bol. S. P. Q. 2007, 107, 47.

45. A produtividade de um fator é razão entre quantidade de produto e a quantidade de fator de produção usado, por exemplo, a produtividade do trabalho é muito discutida nas sociedades industrializadas.
46. Steinbach, A.; Winkerbach, R.; Chem. Eng. 2000, Abril, 94.

47. Koleske, J. V. Em Kent and Riegel's Handbook of Industrial Chemistry and Biotechnology; Kent, J. A., ed.; $11^{\text {th }}$ ed., Springer: Nova Iorque, 2007, p. 63-82.

48. Laidler, K. J.; The World of Physical Chemistry, Oxford UP: Oxford, 1995.

49. Lateralmente, é interessante notar que a inflexão da Biologia no sentido da Biologia Sistémica, presentemente em curso (ver, p. ex.: Kipp, E.; Liebermeister, W.; Wierling, C.; Kowald, A.; Lehrach, H.; Herwig, R.; Systems Biology - A Textbook, Wiley-VCH: Weinheim, 2009), ocorre em paralelo com a mudança de postura da Química para implementação da QV.

50. Shreve, R. N.; Brink Jr, J. A.; Chemical Process Industries, $4^{\text {th }}$ ed., McGraw-Hill: Nova Iorque, 1977, p. 296-297.

51. Riegel's Handbook of Industrial Chemistry; Kent, J. A., ed.; $8^{\text {th }}$ ed., Van Nostrand: Nova Iorque, 1983, p.132.

52. Machado, A. A. S. C.; Química - Bol. S. P. Q. 2006, 103, 45.

53. Machado, A. A. S. C.; Química-Bol. S. P. Q. 2009, 113, 25

54. Machado, A. A. S. C.; Química - Bol. S. P. Q. 2010, 118, 41.

55. Phillips, A.; Chem. Britain 1977, 13, 471.

56. Este valor corresponde a uma capacidade média: há instalações que produzem mais do dobro!

57. Sheldon, R. Em Green Chemistry in the Pharmaceutical Industry; Dunn, P. J.; Wells, A. S.; Williams, M. T., eds.; Wiley-VCH: Weinheim, 2010, p. 1-20.

58. A hidrogenação catalítica, inventada por Sabatier, em 1905, é a exceção a esta "regra"!

59. Landa, M. de; A Thousand Years of Nonlinear History, Swerve: Nova Iorque, 2000.

60. Breslow, R; Tirrell, M.; Beyond the Molecular Frontier - Challenges for Chemistry and Chemical Engineering, NAP: Washington, 2003.

61. Winterton, N.; Green Chem. 2001, 3, G73.

62. Anastas, P. T.; Zimmerman, J. B.; Environ. Sci. Technol. 2003, 37, 95A.

63. STS Education - International Perspectives on Reform, Solomon, J.; Aikenhead, G., eds.; Teachers College Press: Nova Iorque, 1994.

64. Hodson, D.; Int. J. Sci. Educ. 2003, 25, 645. 